\title{
Visible-Light-Driven $\mathrm{SO}_{4}{ }^{2-} / \mathrm{TiO}_{2}$ Photocatalyst Synthesized from Binh Dinh (Vietnam) Ilmenite Ore for Rhodamine B Degradation
}

\author{
Tan Lam Nguyen, ${ }^{1}$ Viet Dinh Quoc, ${ }^{1}$ Thi Lan Nguyen, ${ }^{1}$ Thi Thanh Thuy Le, ${ }^{1}$ \\ Thanh Khan Dinh, ${ }^{2}$ Van Thang Nguyen $\mathbb{D}^{1},{ }^{1}$ and Phi Hung Nguyen $\mathbb{D}^{3}$ \\ ${ }^{1}$ Faculty of Natural Sciences, Quy Nhon University, 55000, Vietnam \\ ${ }^{2}$ Faculty of Physics, University of Science and Education, The University of Danang, 50000, Vietnam \\ ${ }^{3}$ QNU Institute of Educational Sciences (QNIES), Quy Nhon University, 55000, Vietnam
}

Correspondence should be addressed to Van Thang Nguyen; nguyenvanthang@qnu.edu.vn

and Phi Hung Nguyen; nguyenphihung@qnu.edu.vn

Received 12 August 2020; Revised 31 December 2020; Accepted 21 January 2021; Published 4 February 2021

Academic Editor: P. Davide Cozzoli

Copyright (c) 2021 Tan Lam Nguyen et al. This is an open access article distributed under the Creative Commons Attribution License, which permits unrestricted use, distribution, and reproduction in any medium, provided the original work is properly cited.

\begin{abstract}
A low-cost and simplistic approach for the synthesis of nanosized $\mathrm{SO}_{4}{ }^{2-} / \mathrm{TiO}_{2}$ photocatalyst was successfully performed using Binh Dinh ilmenite ore and $\mathrm{H}_{2} \mathrm{SO}_{4}$ as titanium and sulfur sources, respectively. The experimental results indicate that the obtained material exists in the form of particles with a size of about $22 \mathrm{~nm}$ and has a specific surface area of about $49 \mathrm{~m}^{2} \mathrm{~g}^{-1}$. Compared with the $\mathrm{TiO}_{2}$ sample, the $\mathrm{SO}_{4}^{2-} / \mathrm{TiO}_{2}$ sample shows much higher photocatalytic degradation of rhodamine $\mathrm{B}$ ( $\mathrm{RhB}$ ) under the sunlight irradiation. In more details, the nanosized $\mathrm{SO}_{4}{ }^{2-} / \mathrm{TiO}_{2}$ sample obtained is capable of completely decomposing $\mathrm{RhB}$ after 9 hours of irradiation by a $60 \mathrm{~W}$ LED lamp with a corresponding intensity of 9,500 Lux. However, when the $\mathrm{SO}_{4}^{2-} / \mathrm{TiO}_{2}$ is irradiated by the sunlight with the intensity of 65,000 Lux, it only takes 2 hours to completely decompose rhodamine B (RhB), facilitating the use of $\mathrm{SO}_{4}{ }^{2-} / \mathrm{TiO}_{2}$ as a potential photocatalyst for the $\mathrm{RhB}$ photodegradation.
\end{abstract}

\section{Introduction}

Coupled with the exploitation of resources to produce a series of different products to serve life, people have been releasing many pollutants into the environment. Among these pollutants, the persistent organic compounds in the water environment are substances that have negative impacts on humans as well as all other living creatures on earth. In order to meet the urgent requirement for waterwaste treatment, a variety of water treatment technologies have been proposed such as adsorption [1-3], microwave catalysis $[4,5]$, and advanced oxidation processes including photocatalysis [6].

In recent years, the interest in the heterogeneous photocatalysis, which allows the use of the sunlight for the photocatalytic degradation of organic pollutants, has noticeably increased due to their potential applications in the water remediation. Compared to other water treatment technologies, this technology has more advantages in terms of envi- ronmental benefits and operation costs. Thus, photocatalysis is considered one of the most promising technologies to replace the current wastewater treatment technologies in the near future [7-9].

From a practical point of view, a desirable semiconductor for photocatalysis should have the following properties: (i) high photostability, (ii) low toxicity, (iii) suitable bandgap, (iv) resistance to photocorrosion, and (v) affordable fabrication costs [10]. In this respect, among the reported candidates as photocatalysts like $\mathrm{ZnO}-[11], \mathrm{WO}_{3}-[12]$, CdS- [13], $\mathrm{MoS}_{2-}$ [14], $\mathrm{BiVO}_{4}$ - $^{-15}$ ], and $\mathrm{TiO}_{2}$-based materials turn out to be one of the highly promising due to its excellent physical and chemical properties including high photocatalytic activity, nontoxicity, high thermal and chemical stability, and high reproducibility $[16,17]$.

However, the main reason that limits the use of $\mathrm{TiO}_{2}$ for the photodegradation in wastewater treatment under solar irradiation is its large bandgap $(3.20 \mathrm{eV}$ for anatase, $3.0 \mathrm{eV}$ 


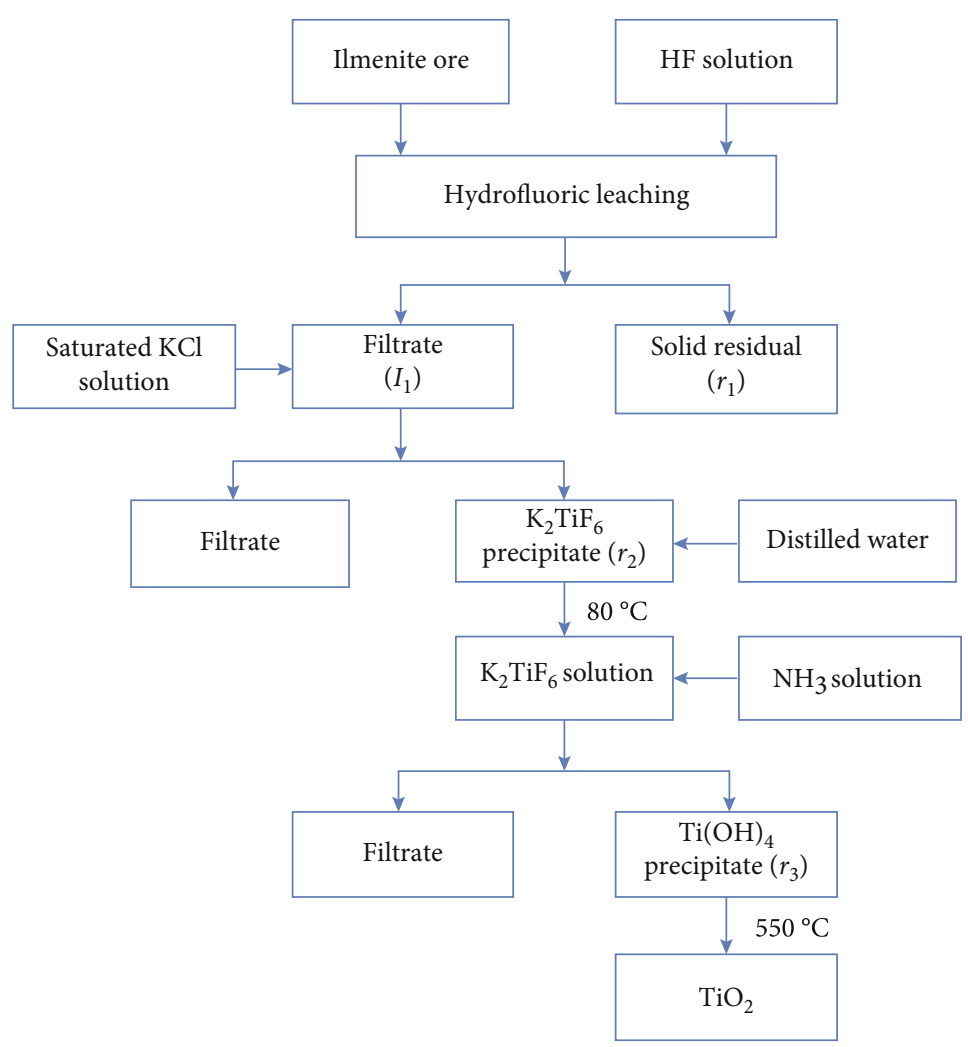

FIgure 1: Process flow for the synthesis of $\mathrm{TiO}_{2}$ nanoparticles from Binh Dinh ilmenite ore.

for rultile, and about $3.2 \mathrm{eV}$ for brookite). In fact, $\mathrm{TiO}_{2}$ can only be activated upon irradiation with a photon of light $<$ $390 \mathrm{~nm}$, which only accounting for 3-5\% of the solar spectrum. Hence, it is highly desirable to extend the light response of $\mathrm{TiO}_{2}$ towards the visible region, enhancing its photocatalytic activity under the visible light irradiation. This can be achieved by (i) metal doping [18-20], (ii) nonmetal doping [19-22], and designing composites based on $\mathrm{TiO}_{2}$ [23-33].

In this present work, $\mathrm{TiO}_{2}$ was first successfully synthesized from Binh Dinh (Vietnam) ilmenite ore to reduce the fabrication costs of $\mathrm{TiO}_{2}$. After that, the obtained $\mathrm{TiO}_{2}$ was hydrothermalized with $\mathrm{H}_{2} \mathrm{SO}_{4}$ to fabricate the $\mathrm{SO}_{4}{ }^{2-} / \mathrm{TiO}_{2}$ with the aim to extend the light response of $\mathrm{TiO}_{2}$ in the visible light region, enhancing its photocatalytic activities under the visible light irradiation. This work is devoted to investigating the effect of the $\mathrm{SO}_{4}{ }^{2-}$ doping on the structural, optical, and photocatalytic activities for the $\mathrm{RhB}$ degradation of $\mathrm{TiO}_{2}$.

\section{Experiments}

2.1. Preparation of Nanosized $\mathrm{TiO}_{2}$ from Binh Dinh Ilmenite Ore. Ilmenite ore, which was taken from Binh Dinh Minerals Joint Stock Company, was used as the starting material for the synthesis of the nanosized $\mathrm{TiO}_{2}$. In order to prepare the nanosized $\mathrm{SO}_{4}{ }^{2-} / \mathrm{TiO}_{2}$, the nanosized $\mathrm{TiO}_{2}$ was fabricated by the hydrolysis of ilmenite ore with hydrofluoric acid in three steps which is summarized as in Figure 1:
(Step 1) $10 \mathrm{~g}$ of ilmenite ore (titanium accounting for $52 \%$ of $\mathrm{TiO}_{2}$ ) and $70 \mathrm{~mL} \mathrm{HF} 20 \%$ (diluted from HF 48\%, Sigma-Aldrich) were put into a plastic beaker and magnetically stirred with a speed of $300 \mathrm{rpm}$ for 5 hours before settling and filtering to remove the solid residue $\left(r_{1}\right)$ and collect the filtrate $\left(l_{1}\right)$

(Step 2) $\mathrm{KCl}$ saturated solution, which was diluted from $99 \% \mathrm{KCl}_{(\mathrm{s})}$, Sigma-Aldrich, was slowly added into the filtrate $\left(l_{1}\right)$ under continously stirring, leading to the formation of a white $\mathrm{K}_{2} \mathrm{TiF}_{6}$ precipitate. With the aim at eliminating the impurities and purify the $\mathrm{K}_{2} \mathrm{TiF}_{6}$ precipitate, the precipitate was filtered and dissolved in hot water at $80^{\circ} \mathrm{C}$ before rapidly cooled down to room temperature to obtain again the $\mathrm{K}_{2} \mathrm{TiF}_{6}$ precipitate $\left(r_{2}\right)$. The obtained $\mathrm{K}_{2} \mathrm{TiF}_{6}$ precipitate was dried at $105^{\circ} \mathrm{C}$ for 2 hours

(Step 3) $5 \mathrm{~g}$ of the $\mathrm{K}_{2} \mathrm{TiF}_{6}$ precipitate was dissolved in $500 \mathrm{~mL}$ of distilled water at $80^{\circ} \mathrm{C}$ before slowly adding $4 \mathrm{M} \mathrm{NH} \mathrm{NH}_{3}$ solution (prepared from ammonium hydroxide solution 28\%, SigmaAldrich) until $\mathrm{pH}=9$. At the end of the hydrolysis process, the suspension was filtrated and washed on a vacuum filter to collect $\mathrm{Ti}(\mathrm{OH})_{4}$ solid $\left(r_{3}\right)$, which was then dried at $105^{\circ} \mathrm{C}$ for 2 hours before annealing at $550^{\circ} \mathrm{C}$ for 3 hours to obtain the nanosized $\mathrm{TiO}_{2}$ (denoted as $\mathrm{TiO}_{2}$ ) 


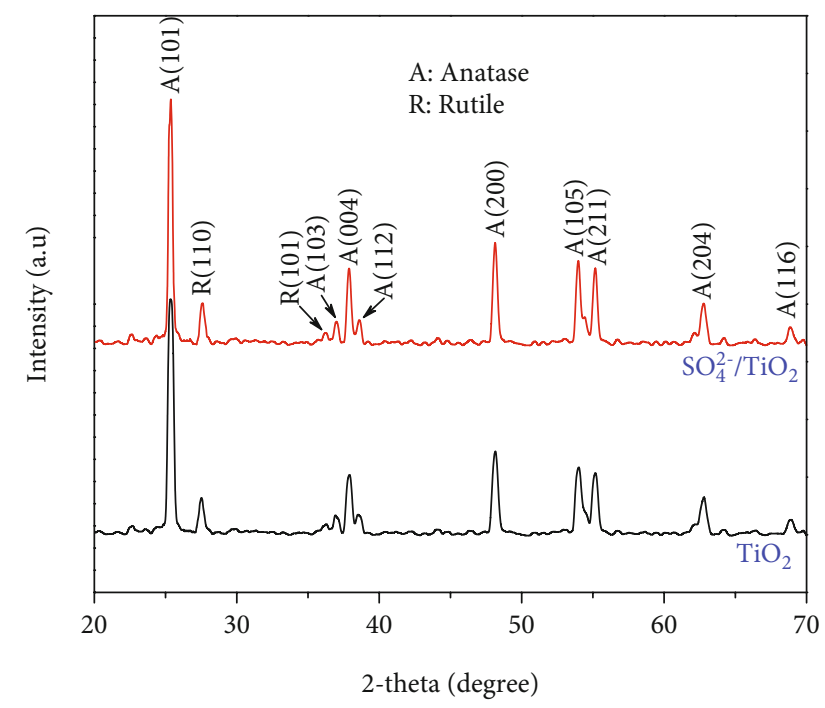

Figure 2: XRD patterns for $\mathrm{TiO}_{2}$ and $\mathrm{SO}_{4}{ }^{2-} / \mathrm{TiO}_{2}$.

2.2. Synthesis of Nanosized $\mathrm{SO}_{4}{ }^{2-} / \mathrm{TiO}_{2} .1 \mathrm{~g}$ aboveobtained $\mathrm{TiO}_{2}$ was put into a Teflon flask before adding $150 \mathrm{~mL}$ of $\mathrm{H}_{2} \mathrm{SO}_{4} 0.7 \mathrm{M}$ (diluted from $\mathrm{H}_{2} \mathrm{SO}_{4} 99 \%$, Sigma-Aldrich). After that, the mixture was hydrothermalized at $170^{\circ} \mathrm{C}$ for 24 hours using an autoclave. At the end of the hydrothermal process, the suspension was washed and dried at $105^{\circ} \mathrm{C}$ for 2 hours, obtaining the nanosized $\mathrm{SO}_{4}{ }^{2-} / \mathrm{TiO}_{2}$ material.

2.3. Catalyst Characterization. XRD patterns of obtained samples were recorded at room temperature in the $2 \theta$ range of 20$70^{\circ}$ using a $\mathrm{D} 8 \mathrm{Advance}$ Brucker diffractometer $(\mathrm{Cu} \mathrm{K} \alpha$ radiation, $\lambda=1.540 \AA$ ); operated at $40 \mathrm{kV}$ and $0.04 \mathrm{~A}$. The average crystallite size was determined from XRD measurements by applying the Debye-Scheerer equation: $\bar{r}=(0.89 . \lambda) /(\beta \cdot \cos \theta)$ [34], to the highest intensity peak (101), which was fitted with Origin software to identify the full-width-at-half-maximum and the peak position.

FT-IR spectra were collected by means of an IRAffinity1S spectrometer in the spectra range of $4000-400 \mathrm{~cm}^{-1}$. The UV-vis diffuse reflectance spectra were recorded using U4100 UV-Vis-NIR Hitachi.

The specific surface area and porous properties of obtained sample were determined by $\mathrm{N}_{2}$ adsorptiondesorption isotherms methods at $77 \mathrm{~K}$ (BET) using Micromeritics ASAP 2000.

XPS measurements were carried out on the ESCALab 250 spectrometer (Thermo VG, UK) using $\mathrm{Al} \mathrm{K} \alpha$ radiation with the photon energy of $1486.6 \mathrm{eV}$ to identify the element, composition, and oxidation state on the surface of the photocatalyst. A sufficient amount of powder was immobilized on carbon tape before loading into the XPS chamber. Survey scans were acquired using $0.48 \mathrm{eV}$ resolution energy and $0.1 \mathrm{eV} / \mathrm{step}$ with charge neutralization. The peaks positions were calibrated according to the C1s peak at $284.6 \mathrm{eV}$.

Particle size and surface morphology of obtained samples were investigated by SEM and TEM using Nano SEM-450 and JOEL-JEM-1010, respectively. The measurement of photoluminescence (PL) was performed by a spectrometer
Horiba FL3-22 over the wavelength of 400-600 nm with a $450 \mathrm{~W}$ Xenon lamp (the excitation wavelength of $380 \mathrm{~nm}$ ).

2.4. Photocatalytic Measurements for $\mathrm{SO}_{4}^{2-} / \mathrm{TiO}_{2}$. Photodegradation of $\mathrm{RhB}$ was performed in order to evaluate the photocatalytic activities of the $\mathrm{TiO}_{2}$ and $\mathrm{SO}_{4}{ }^{2-} / \mathrm{TiO}_{2}$ photocatalysts. $60 \mathrm{mg} \mathrm{SO}{ }_{4}^{2-} / \mathrm{TiO}_{2}$ photocatalyst was added into a $250 \mathrm{~mL}$ containing $100 \mathrm{~mL} \mathrm{RhB}$ solution $(10 \mathrm{mg} / \mathrm{L})$. The suspension was stirred for 60 minutes in the dark to reach the adsorption-desorption equilibrium before irradiating the mixture by the $60 \mathrm{~W}$ LED lamp with a corresponding intensity of 9,500 Lux or the sunlight with the intensity of 65,000 Lux. After that, $2 \mathrm{~mL}$ of the solution was taken out every 60 minutes and centrifuged (6000 rpm, 20 minutes) for subsequent measurements. The solution obtained after centrifugation was protected in the dark before determining the concentration of RhB with a UV-Vis spectrometer (UV-1800 Shimazu) by monitoring the absorbance of RhB at $553 \mathrm{~nm}$.

$\mathrm{RhB}$ photodegradation efficiency is calculated by the following formula:

$$
H=\frac{C_{0}-C_{t}}{C_{0}} \times 100
$$

In which, $C_{0}$ is the initial concentration of RhB before illumination and $C_{t}$ is the remaining concentration of $\mathrm{RhB}$ after each corresponding irradiation time.

\section{Results and Discussions}

3.1. Determination of Crystal Phase Structure by X-Ray Diffraction. Figure 2 shows the XRD patterns of the $\mathrm{TiO}_{2}$ and $\mathrm{SO}_{4}^{2-} / \mathrm{TiO}_{2}$ samples. As can be seen in Figure 2, the two XRD patterns exhibit the characteristic diffraction peaks of both the anatase and rutile phases. In more details, the diffraction peaks at $2 \theta=25.26,37.78,38.56,48.5$, and $53.90^{\circ}$ are characteristic peaks for the anatase-type $\mathrm{TiO}_{2}$ (JCPDS 211272) while the diffraction peaks at $2 \theta=27.50$ and $53.9^{\circ}$ are typical peaks for the rutile-type $\mathrm{TiO}_{2}(J C P D S$ 21-1276) and are indexed as (110) and (101).

The proportion of the anatase and rutile phases in the obtained samples is determined by the following expression [35]:

$$
\begin{aligned}
X_{\text {rutile }} & =\left(1+0.79\left(\frac{I_{A}}{I_{R}}\right)\right)^{-1}, \\
X_{\text {anatase }} & =1-X_{\text {rutile }},
\end{aligned}
$$

where $X_{\text {rutile }}$ and $X_{\text {anatase }}$ are the percentage (\%) of the rutile and anatase phases, $I_{A}$ is the maximum peak intensity corresponding to the crystal face (101) of the anatase phase, and $I_{R}$ is the maximum peak intensity corresponding to the crystal face (110) of the rutile phase.

Table 1 shows the average crystallite size, the ratio of the anatase to rutile phase, the crystallinity, the specific surface area, and the $\mathrm{RhB}$ photodegradation efficiency for the $\mathrm{TiO}_{2}$ and $\mathrm{SO}_{4}{ }^{2-} / \mathrm{TiO}_{2}$ samples. As can be seen in Table 1 , the ratio of the anatase to rutile phase hardly changes while there is a 
TABLE 1: Characteristics for $\mathrm{TiO}_{2}$ and $\mathrm{SO}_{4}^{2-} / \mathrm{TiO}_{2}$.

\begin{tabular}{lccccc}
\hline Sample & $\begin{array}{c}\text { Average crystallite } \\
\text { size }(\mathrm{nm})\end{array}$ & $\begin{array}{c}\text { Ratio of the anatase } \\
\text { to rutile phase }\end{array}$ & $\begin{array}{c}\text { Specific surface area } \\
\left(\mathrm{m}^{2} \mathrm{~g}^{-1}\right)\end{array}$ & $\begin{array}{c}\text { RhB photodegradation efficiency (\%) } \\
\text { After 9 hours of the visible } \\
\text { light irradiation }\end{array}$ & $\begin{array}{c}\text { After 2 hours of the } \\
\text { sunlight irradiation }\end{array}$ \\
\hline $\mathrm{TiO}_{2}$ & 19.09 & $83.16 / 16.84$ & 89.4135 & 11.77 & 26.09 \\
$\mathrm{SO}_{4}{ }^{2-} / \mathrm{TiO}_{2}$ & 22.19 & $82.95 / 17.05$ & 49.9120 & 99.47 & 99.63 \\
\hline
\end{tabular}

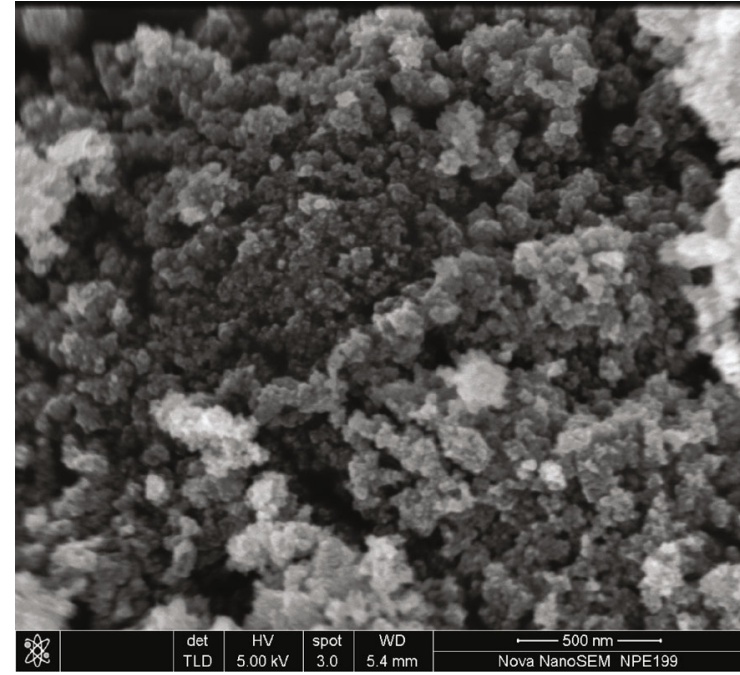

(a)

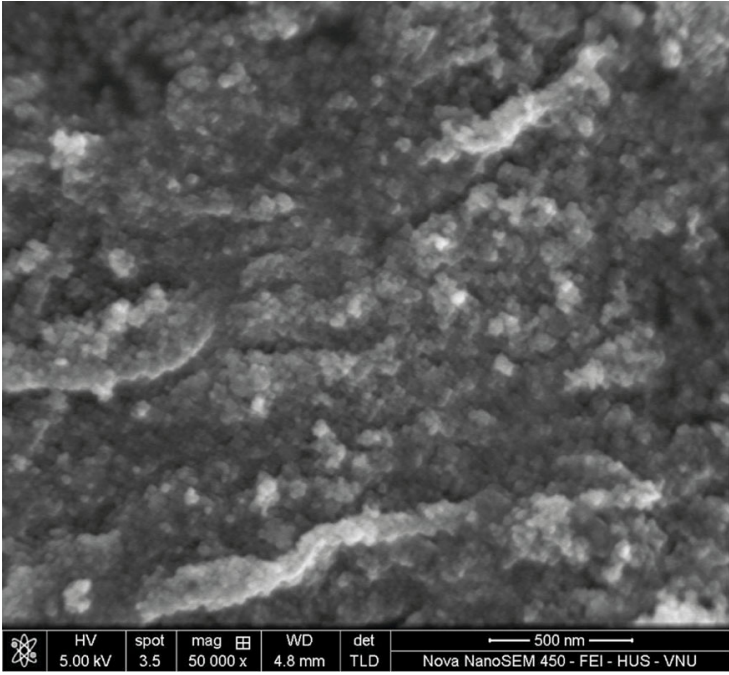

(b)

FIgURE 3: SEM images for (a) $\mathrm{TiO}_{2}$ and (b) $\mathrm{SO}_{4}{ }^{2-} / \mathrm{TiO}_{2}$.

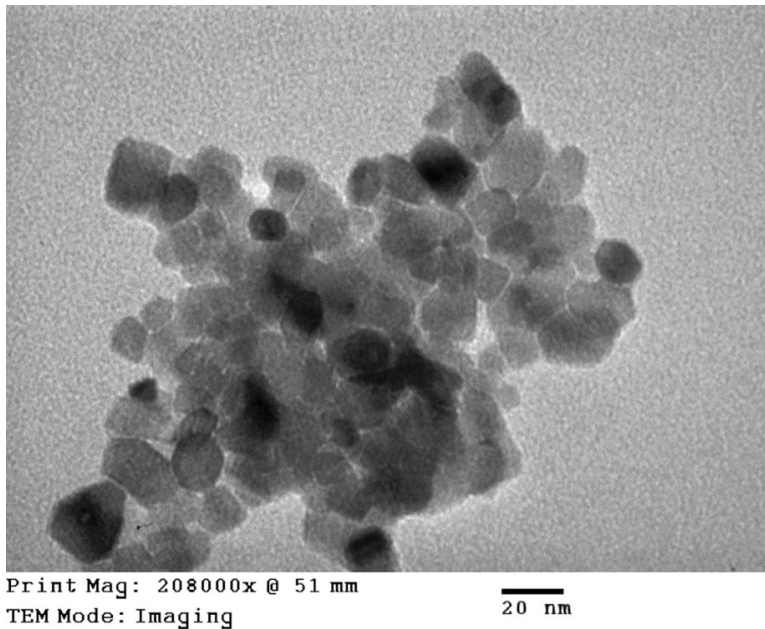

(a)

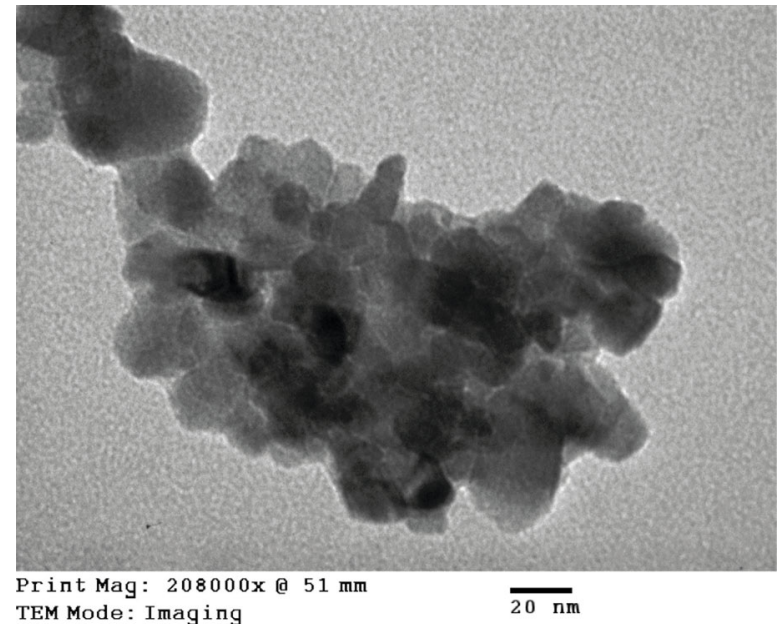

(b)

Figure 4: TEM images for (a) $\mathrm{TiO}_{2}$ and (b) $\mathrm{SO}_{4}{ }^{2-} / \mathrm{TiO}_{2}$.

slight decrease in the crystallinity of the obtained sample after the $\mathrm{SO}_{4}{ }^{2-}$ doping. This suggests that the hydrothermal process of the $\mathrm{TiO}_{2}$ in $\mathrm{H}_{2} \mathrm{SO}_{4}$ at $170^{\circ} \mathrm{C}$ for 24 hours enhances the crystallinity of the $\mathrm{SO}_{4}{ }^{2-} / \mathrm{TiO}_{2}$ obtained.

3.2. Surface Morphology and Porous Properties. The particle size and surface morphology of the $\mathrm{TiO}_{2}$ and $\mathrm{SO}_{4}{ }^{2-} / \mathrm{TiO}_{2}$ samples were characterized by SEM and TEM. Obtained SEM and TEM images are presented in Figures 3 and 4, respectively.
SEM images shown in Figure 3 indicate that all samples exist in the form of granules and are quite uniform with relatively small particle size.

TEM images shown in Figure 4 indicate that the presence of $\mathrm{SO}_{4}{ }^{2-}$ on the surface of $\mathrm{TiO}_{2}$ not only increases the particle size but also changes the surface morphology of the $\mathrm{SO}_{4}{ }^{2-} / \mathrm{TiO}_{2}$ sample in comparison with the unmodified $\mathrm{TiO}_{2}$.

It is well known that the photocatalytic degradation process of organic pollutants is affected by their adsorption on the photocatalyst; thus, the impact of the surface area is 


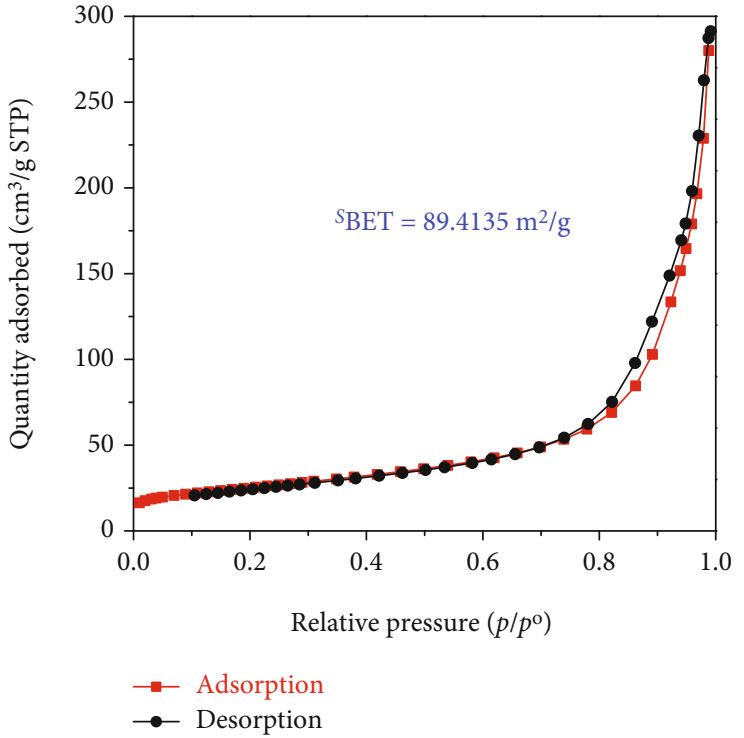

(a)

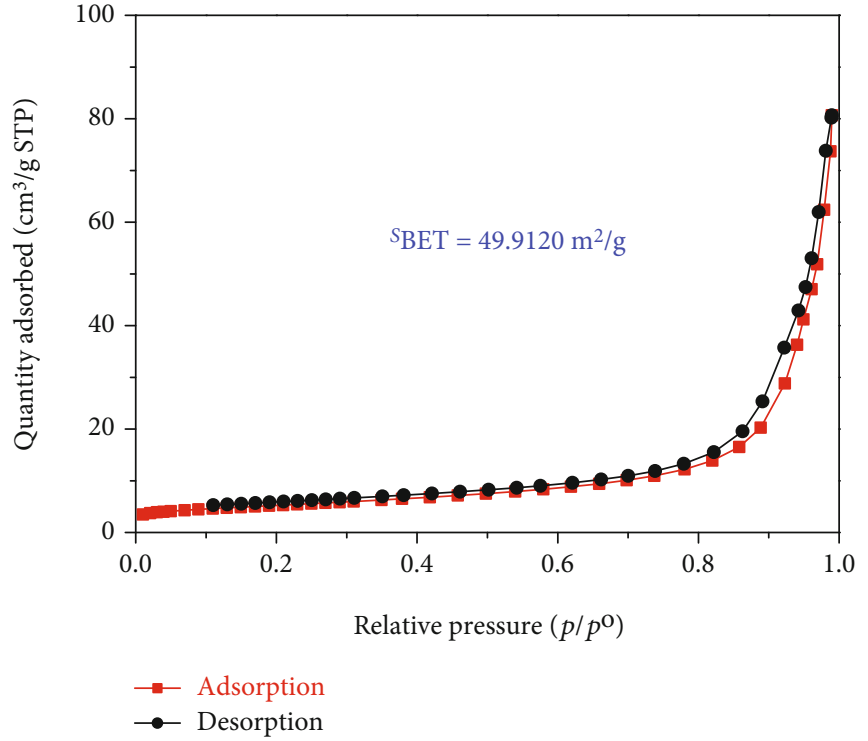

(b)

Figure 5: The $\mathrm{N}_{2}$ adsorption-desorption isotherms at $77 \mathrm{~K}$ for (a) $\mathrm{TiO}_{2}$ and (b) $\mathrm{SO}_{4}{ }^{2-} / \mathrm{TiO}_{2}$.

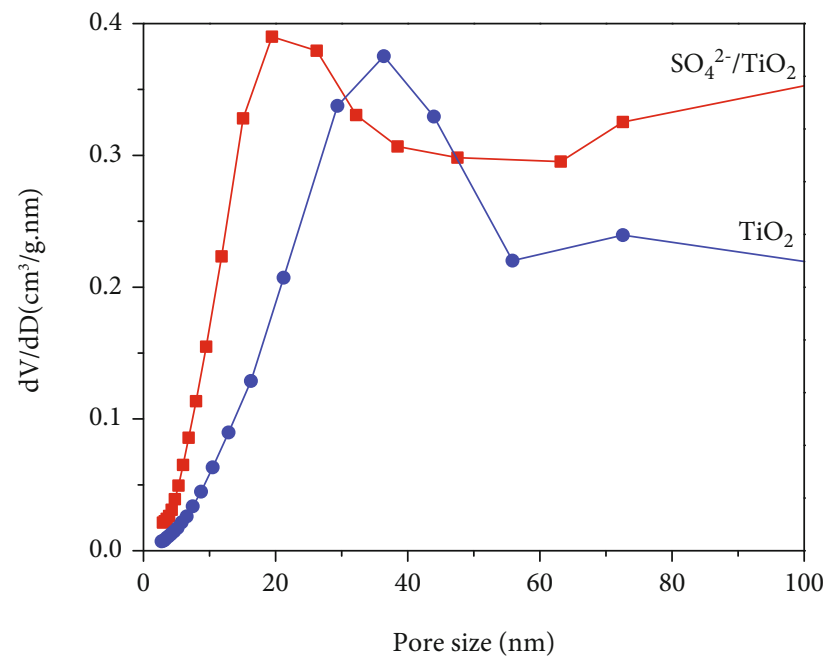

Figure 6: Pore size distribution of $\mathrm{TiO}_{2}$ and $\mathrm{SO}_{4}{ }^{2-} / \mathrm{TiO}_{2}$.

critical in the entire process. In this present work, the porous properties and specific surface area of the obtained samples were characterized by $\mathrm{N}_{2}$ adsorption-desorption isotherms methods using Brunauer-Emmett-Teller (BET) surface area analysis and the results are shown in Figure 5.

The adsorption-desorption isotherms of both the $\mathrm{TiO}_{2}$ and $\mathrm{SO}_{4}{ }^{2-} / \mathrm{TiO}_{2}$ samples shown in Figure 5 had characteristic features of the type IV isotherm with the type $\mathrm{H} 3$ loop according to IUPAC showing structure of the material samples consist by an assemblage of particles joined together. Indeed, the mall hysteresis loops occur in the area of relative pressure $\left(p / p^{0}=0.7-0.98\right)$ higher compared with materials of mesoporous construction (their hysteresis loops usually present at relative pressure zones $p / p^{0}=0.4-0.8$ ). This suggests that the capillary structure inside the particles of the $\mathrm{TiO}_{2}$ and $\mathrm{SO}_{4}{ }^{2-}$ materials is not dominant (the material particles are in the solid form). In other words, the materials have the dominant particle rather than porosity. The adsorptiondesorption isothermal hysteresis loops of the two samples shown in Figure 5 are caused by adsorption-desorption in the interparticle space with dimensions in the range of 20 $100 \mathrm{~nm}$ as determined by the capillary distribution curves in Figure 6. In addition, the peak in the capillary distribution curve of the $\mathrm{SO}_{4}{ }^{2-} / \mathrm{TiO}_{2}$ material shifts significantly towards the small capillary size compared with the $\mathrm{TiO}_{2}$ material. This can be explained by the fact that the modification of the $\mathrm{TiO}_{2}$ materials leads to an increase in surface defects and a decrease in surface bond saturation, and thereby decreasing the strength of free particles and increasing the interaction between particles. As the results, the specific surface area of the particles significantly decreases $\left(89.4135 \mathrm{~m}^{2} / \mathrm{g}\right.$ and $49.9120 \mathrm{~m}^{2} / \mathrm{g}$ for the $\mathrm{TiO}_{2}$ and $\mathrm{SO}_{4}{ }^{2-} / \mathrm{TiO}_{2}$ materials, 


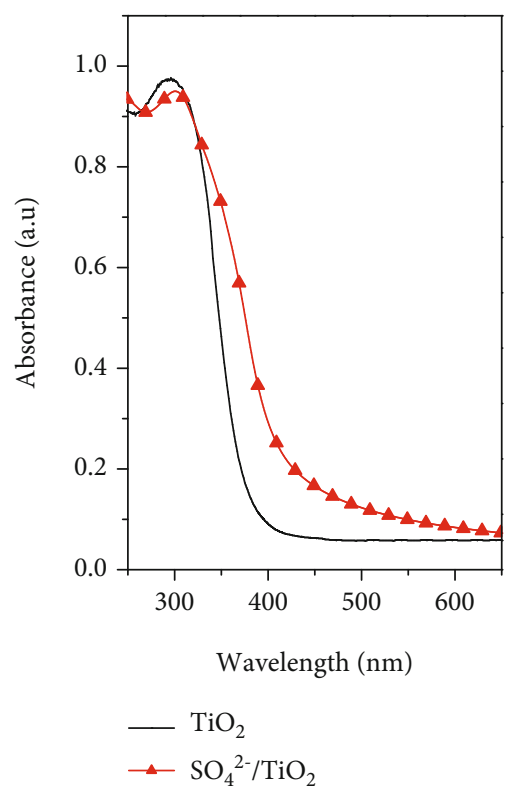

(a)

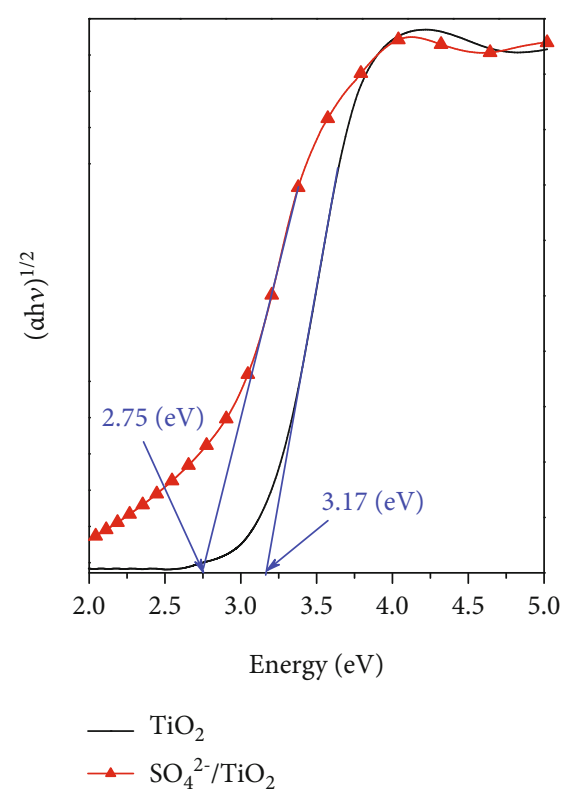

(b)

FIgURE 7: (a) UV-Vis diffuse reflectance spectra and (b) $E_{g}$ versus Kubelka-Munk function for $\mathrm{TiO}_{2}$ and $\mathrm{SO}_{4}{ }^{2-} / \mathrm{TiO}_{2}$.

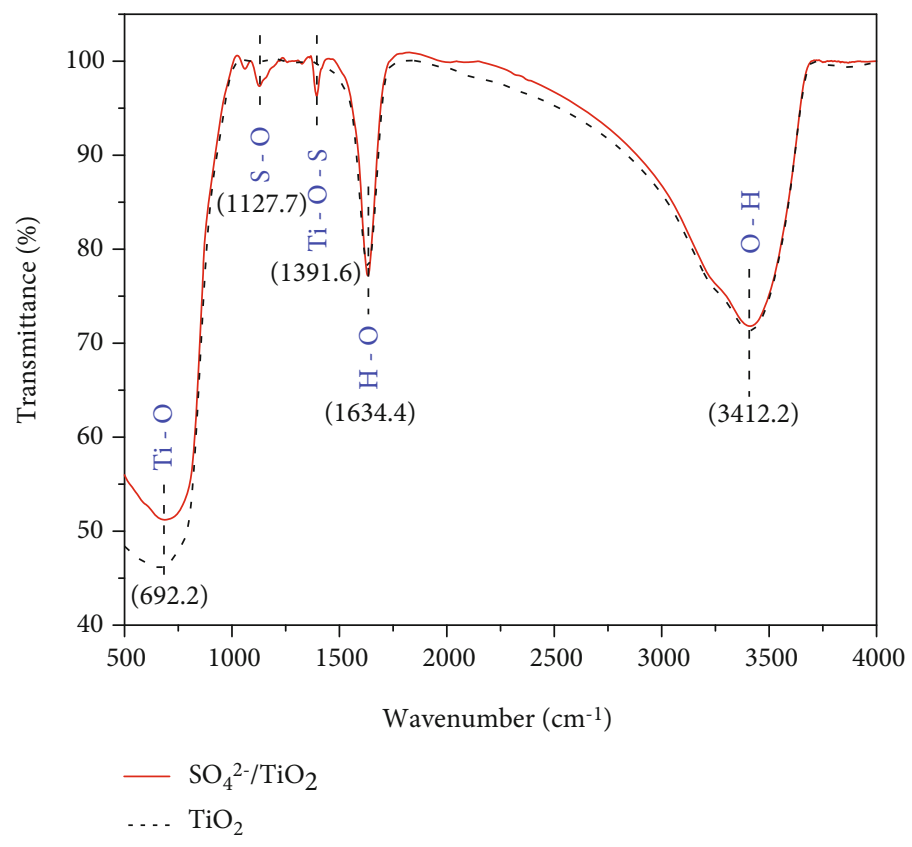

FIgURE 8: FT-IR spectra for $\mathrm{TiO}_{2}$ và $\mathrm{SO}_{4}{ }^{2-} / \mathrm{TiO}_{2}$.

respectively) due to the decrease in the spacing between the particles.

3.3. Optical Absorption Capacity. Optical properties of the $\mathrm{TiO}_{2}$ and $\mathrm{SO}_{4}{ }^{2-} / \mathrm{TiO}_{2}$ samples were investigated by $\mathrm{UV}$ Vis DRS and their UV-Vis DRS spectra are shown in Figure $7(\mathrm{a})$. It can be seen that the unmodified $\mathrm{TiO}_{2}$ sample only absorbs photons with the wavelength below $400 \mathrm{~nm}$ while the modified $\mathrm{SO}_{4}{ }^{2-} / \mathrm{TiO}_{2}$ sample can absorb photons in the visible light region with the optical absorption edge spreading to about $550 \mathrm{~nm}$. In other words, compared with the $\mathrm{TiO}_{2}$ sample, the $\mathrm{SO}_{4}{ }^{2-} / \mathrm{TiO}_{2}$ sample has an absorption band shifting to the lower energy region (higher wavelength), thereby probably utilizing more efficiently the visible light.

Kubelka-Munk function was employed to estimate the bandgap energy of the $\mathrm{TiO}_{2}$ and $\mathrm{SO}_{4}{ }^{2-} / \mathrm{TiO}_{2}$ samples by plotting $(\alpha \mathrm{h} v)^{1 / 2}$ as a function of the phonon energy (Figure 7(b)). The bandgap energies of the $\mathrm{TiO}_{2}$ and $\mathrm{SO}_{4}{ }^{2-} / \mathrm{TiO}_{2}$ samples are 3.17 and $2.75 \mathrm{eV}$, respectively. Thus, when modification 


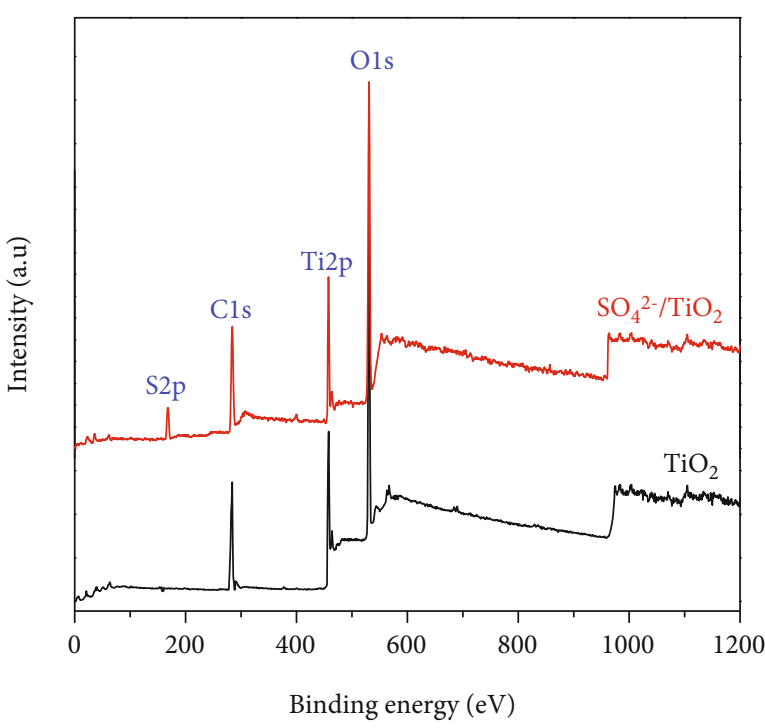

(a)

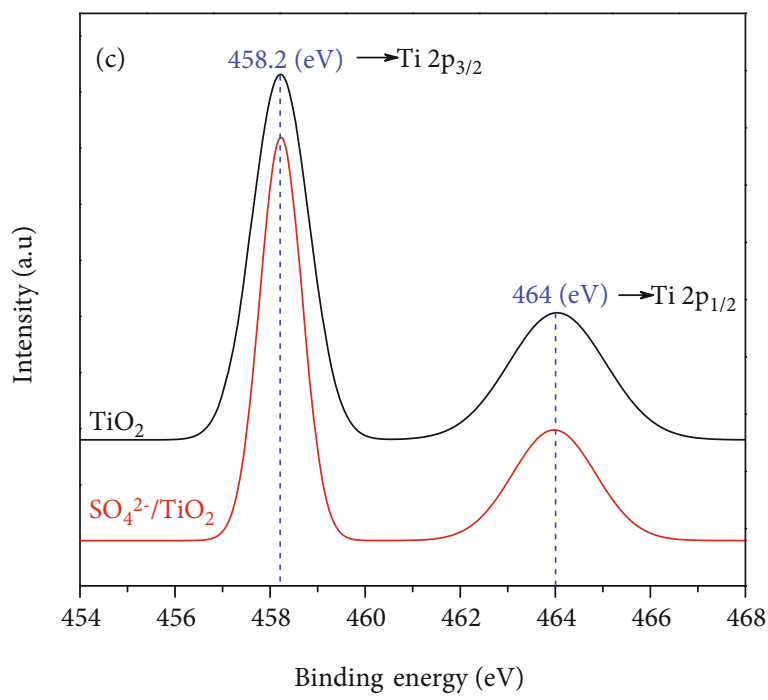

(c)

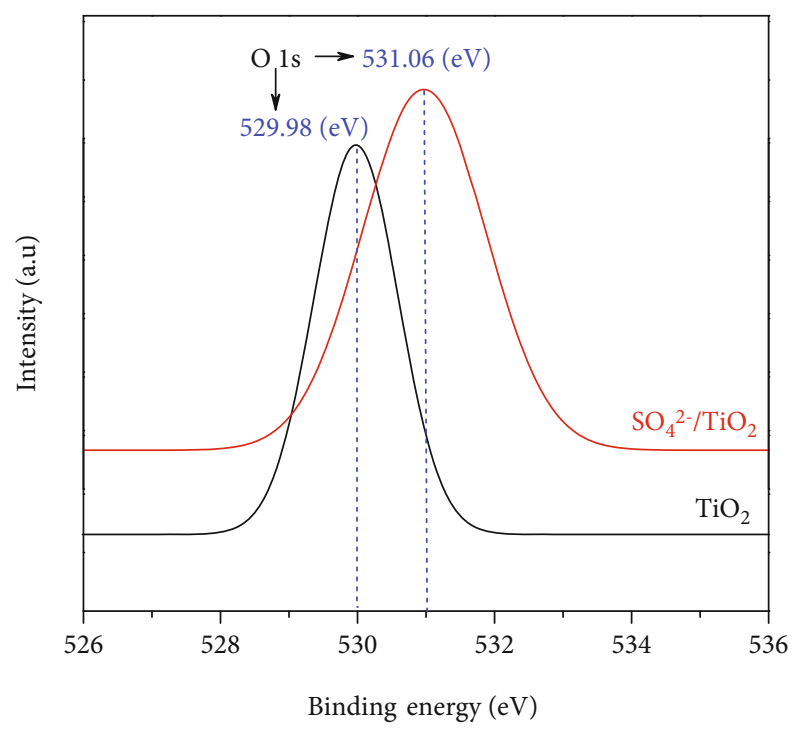

(b)

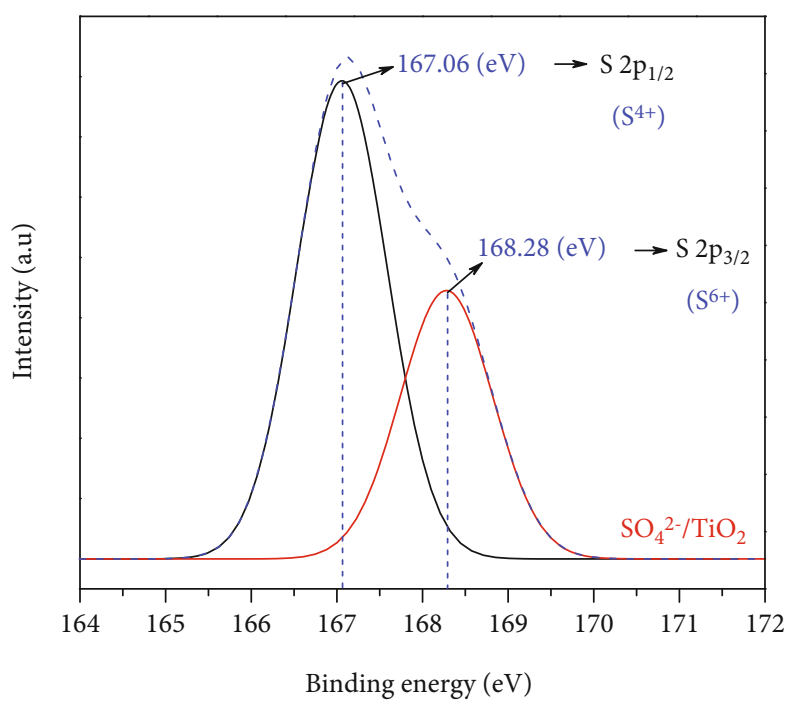

(d)

FIGURE 9: XPS spectra for $\mathrm{TiO}_{2}$ and $\mathrm{SO}_{4}{ }^{2-} / \mathrm{TiO}_{2}$ : (a) XPS survey spectra, (b) O1s spectrum, (c) $\mathrm{Ti} 2 \mathrm{p}_{3 / 2}$ spectrum, and (d) S2 $\mathrm{p}_{3 / 2}$ spectrum.

of $\mathrm{TiO}_{2}$ by sulfur in the form of sulfate ions, the bandgap energy of the obtained sample has been significantly reduced. This is in a good agreement with previous reports [36, 37]. The absorption in the visible light region of the $\mathrm{SO}_{4}{ }^{2-} / \mathrm{TiO}_{2}$ sample is enhanced compared with the undoped $\mathrm{TiO}_{2}$ sample may be attributed to the formation of an intermediate energy level below the conduction band of $\mathrm{TiO}_{2}$ after the $\mathrm{SO}_{4}{ }^{2-}$ doping [38].

3.4. Surface Chemical State of Samples. Bonding characteristics in the obtained samples were characterized by FT-IR and FT-IR spectra are shown in Figure 8.

The FT-IR spectra for both the $\mathrm{TiO}_{2}$ and $\mathrm{SO}_{4}{ }^{2-} / \mathrm{TiO}_{2}$ samples appear modes of oscillation originating from the $\mathrm{OH}$-stretching (around $1634.4 \mathrm{~cm}^{-1}$ ), the $\mathrm{OH}$-bending of adsorbed water (around $3412.2 \mathrm{~cm}^{-1}$ ) $[39,40]$, and tetrahedral/octahedral TiO-stretching (around $692.2 \mathrm{~cm}^{-1}$ ). How- ever, coupled with these peaks, the $\mathrm{SO}_{4}{ }^{2-} / \mathrm{TiO}_{2}$ sample exhibits two additional peaks at 1391.6 and $1127.7 \mathrm{~cm}^{-1}$ which are attributed to the characteristic modes of ocisllation of the $\mathrm{SO}_{4}{ }^{2-}$ with bidentate bond $[41,42]$. This suggests that there is the chemical adsorption or penetration of $\mathrm{SO}_{4}{ }^{2-}$ ions into the crystal lattice of $\mathrm{TiO}_{2}$.

The chemical states of the $\mathrm{TiO}_{2}$ and $\mathrm{SO}_{4}{ }^{2-} / \mathrm{TiO}_{2}$ surfaces were investigated by XPS. Figure 9(a) presents XPS survey spectra of the $\mathrm{TiO}_{2}$ and $\mathrm{SO}_{4}{ }^{2-} / \mathrm{TiO}_{2}$ samples. Compared with the XPS survey spectrum of the $\mathrm{TiO}_{2}$ sample, that of the $\mathrm{SO}_{4}{ }^{2-} / \mathrm{TiO}_{2}$ sample shows an additional peak of $\mathrm{S} 2 \mathrm{p}$, indicating the presence of sulfur in the modified sample. The XPS survey spectra of both samples show a strong peak of C1s at $284.6 \mathrm{eV}$ corresponding to the elemental carbon (graphite) from the substrate. Figure 9(b) shows the XPS O1s core level for the $\mathrm{TiO}_{2}$ and $\mathrm{SO}_{4}{ }^{2-} / \mathrm{TiO}_{2}$ samples. As can be seen, the characteristic peaks are at 529.98 and $531.06 \mathrm{eV}$ of $\mathrm{O} 1 \mathrm{~s}$ in 


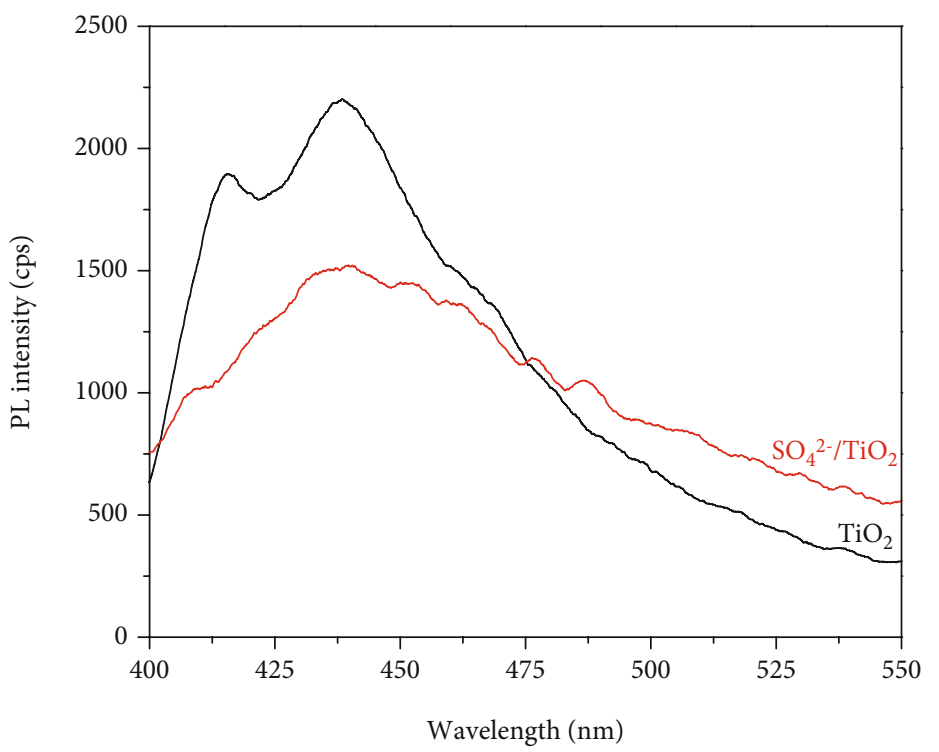

Figure 10: PL spectra of $\mathrm{TiO}_{2}$ and $\mathrm{SO}_{4}{ }^{2-} / \mathrm{TiO}_{2}$.

$\mathrm{TiO}_{2}$ and $\mathrm{SO}_{4}{ }^{2-} / \mathrm{TiO}_{2}$, respectively. The XPS Ti2p core level shown in Figure 9(c) has two characteristic peaks at around $458.2 \mathrm{eV}$ for $\mathrm{Ti} 2 \mathrm{p}_{3 / 2}$ and $464 \mathrm{eV}$ for $\mathrm{Ti} 2 \mathrm{p}_{1 / 2}$, confirming that the valence state of titanium exists in $\mathrm{Ti}^{4+}$ form. Figure 9 (d) shows the S2p doublet core peak locating at $167.06 \mathrm{eV}$ for $\mathrm{S} 2 \mathrm{p}_{1 / 2}$ and $168.28 \mathrm{eV}$ for $\mathrm{S} 2 \mathrm{p}_{3 / 2}$, indicating that the valence states of sulfur are $\mathrm{S}^{4+}$ (in Ti-O-S bonding) and $\mathrm{S}^{6+}$ (in $\mathrm{SO}_{4}{ }^{2-}$ ), respectively, [42]. Hence, the presence of $\mathrm{SO}_{4}{ }^{2-}$ ions on the surface of $\mathrm{TiO}_{2}$ did not significantly affect the peak position at $\mathrm{Ti} 2 \mathrm{p}$ but greatly affected the binding energy of $\mathrm{O} 1 \mathrm{~s}$ and S2p. It is noted that the binding energies of Ti2 $\mathrm{p}_{3 / 2}$ and $\mathrm{O} 1 \mathrm{~s}$ in pure $\mathrm{TiO}_{2}$ are 458.5 and $530.28 \mathrm{eV}$, respectively, and the binding energy of $\mathrm{S}_{2} \mathrm{p}_{3 / 2}$ in pure $\mathrm{SO}_{4}{ }^{2-}$ is $169 \mathrm{eV}$ [43]. The above results show that there is an upward shift in the binding energy of O1s and a downward shift in the binding energy of $\mathrm{S}_{2} \mathrm{p}_{3 / 2}$ (about $0.7 \mathrm{eV}$ ) after the $\mathrm{SO}_{4}{ }^{2-}$ doping. This can be explained by the fact that a part of the electron is transferred from oxygen to sulfur [44], resulting in a change in the valence state of a part $S^{6+}$ to $S^{4+}$ and the formation of a new band in energy structure [37].

The XPS spectra demonstrate the formation of bonds among titanium, oxygen, and sulfur atoms. This result is also consistent with the perception of the connection between the elements shown on the FT-IR spectra in Figure 8.

PL measurements were conducted to evaluate the recombination rate of the photoinduced electrons and holes of the obtained samples. As can be seen shown in Figure 10, the luminescent intensity of the $\mathrm{SO}_{4}{ }^{2-} / \mathrm{TiO}_{2}$ sample is lower than that of the $\mathrm{TiO}_{2}$ sample, indicating a different electron-hole recombination path. This may due to the fact that doping $\mathrm{SO}_{4}{ }^{2-}$ on the surface of $\mathrm{TiO}_{2}$ is suitable for trapping photoinduced electrons and thereby suppressing the recombination of photoinduced elontrons and holes [38]. In a nutshell, the $\mathrm{SO}_{4}{ }^{2-}$ doping on $\mathrm{TiO}_{2}$ improves the charge separation efficiency and consequently promotes the formation of oxidizing agents such as hydroxyl radical, which may increase the photocatalytic activity of the $\mathrm{SO}_{4}{ }^{2-} / \mathrm{TiO}_{2}$ sample.
Based on the results obtained from UV-Vis-DRS spectra (Figure 7), XPS spectra (Figure 9), and PL spectra (Figure 10), it can be proposed that the increase in the photocatalytic activity of the $\mathrm{SO}_{4}{ }^{2-} / \mathrm{TiO}_{2}$ material is due to the synergistic effect between $\mathrm{S}^{+6}\left(\mathrm{SO}_{4}{ }^{2-}\right)$ anchored on the surface and $\mathrm{S}^{4+}$ doped into the crystalline lattice. Electron shifting from oxygen to sulfur atoms creates extra energy levels which lead to a significant reduction in bandgap energy (Figure 7), facilitating the photon absorption in the visible region for better generation of photoinduced electrons $\left(\mathrm{e}^{-}\right)$and holes $\left(\mathrm{h}^{+}\right)$. Consequently, $\mathrm{h}^{+}$moves to the surface to continue to produce $\cdot \mathrm{OH}$ while $\mathrm{e}^{-}$moves to $\mathrm{S}^{6+}\left(\mathrm{SO}_{4}{ }^{2-}\right)$ on the surface of the material before combining with $\mathrm{O}_{2}$ and produces $\mathrm{O}_{2}{ }^{-}$. This reduces the recombination rate of photoinduced electrons $\left(\mathrm{e}^{-}\right)$and holes $\left(\mathrm{h}^{+}\right)$which is consistent with the PL spectra (Figure 10). The generation processes of $\cdot \mathrm{OH}$ and $\mathrm{O}_{2}{ }^{--}$can be described as

$$
\begin{aligned}
& \mathrm{SO}_{4}{ }^{2-} / \mathrm{TiO}_{2}+\mathrm{h} v \longrightarrow \mathrm{SO}_{4}{ }^{2-} / \mathrm{TiO}_{2}+\mathrm{e}^{-}+\mathrm{h}^{+} \\
& \mathrm{OH}^{-}+\mathrm{h}^{+} \longrightarrow \mathrm{OH} \\
& \mathrm{O}_{2}+\mathrm{e}^{-} \longrightarrow \mathrm{O}_{2}^{\bullet-} \\
& \mathrm{O}_{2}^{\cdot-}+\mathrm{H}^{+} \longrightarrow \mathrm{HO}_{2}^{\bullet} \\
& 2 \mathrm{HO}_{2}^{\cdot} \longrightarrow \mathrm{H}_{2} \mathrm{O}_{2}+\mathrm{O}_{2} \\
& \mathrm{H}_{2} \mathrm{O}_{2}+\mathrm{e}^{-} \longrightarrow \cdot{ }^{\circ} \mathrm{OH}+\mathrm{OH}^{-}
\end{aligned}
$$

3.5. Photocatalytic Degradation. Evaluation of RhB photodegradation was conducted as mentioned in Section 2.4 and the $\mathrm{RhB}$ photocatalytic degradation of the blank sample, $\mathrm{TiO}_{2}$, and $\mathrm{SO}_{4}{ }^{2-} / \mathrm{TiO}_{2}$ under the irradiation of the $60 \mathrm{~W}$ LED lamp and the sunlight is shown in Figure 11. It is noted that the $C / C_{0}$ as a function of irradiation time for the blank sample hardly changes under both the visible light and sunlight irradiation, indicating that the presence of $\mathrm{TiO}_{2}$ and $\mathrm{SO}_{4}{ }^{2-} / \mathrm{TiO}_{2}$ plays a major role in the RhB photodegradation. 


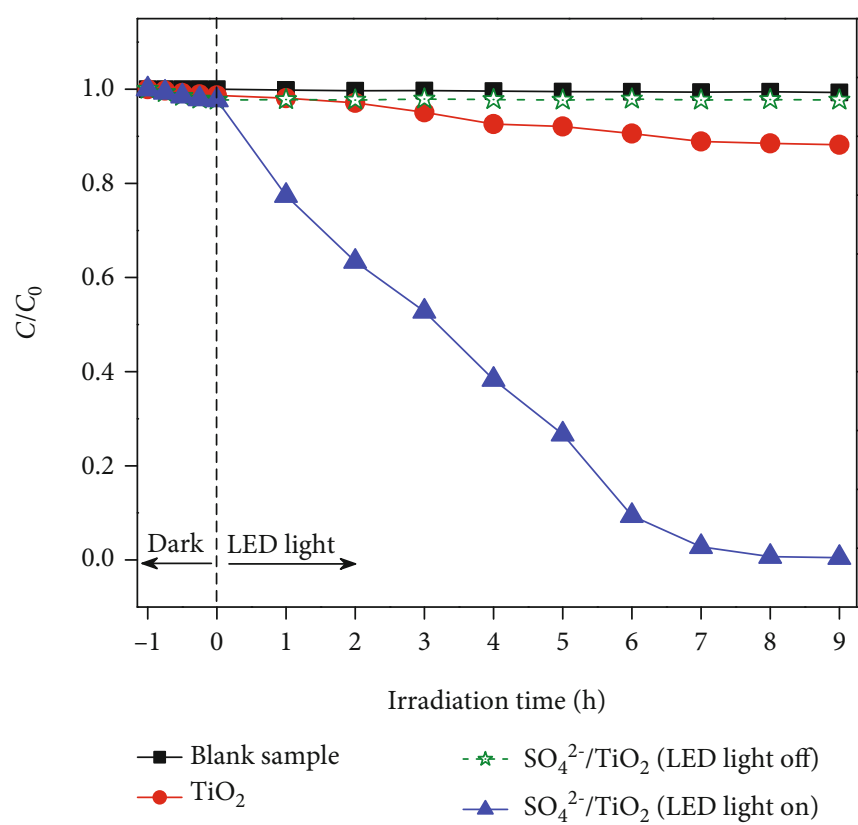

(a)

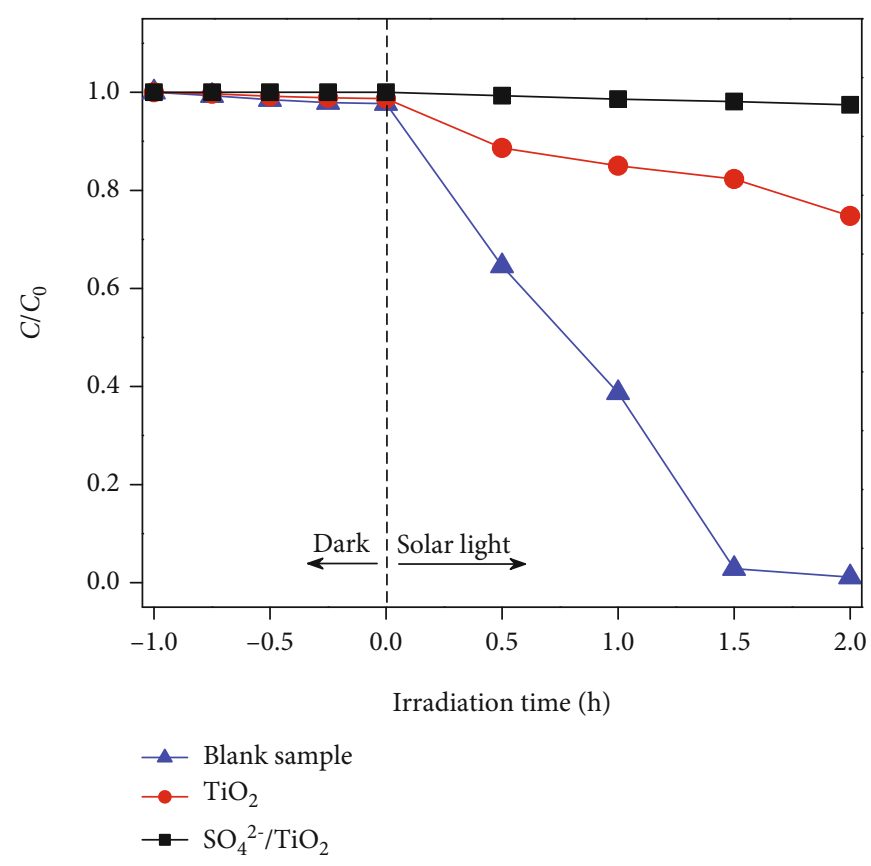

(b)

FIGURE 11: The change in $C / C_{0}$ as a function of irradiation time for the blank sample, $\mathrm{TiO}_{2}$, and $\mathrm{SO}_{4}{ }^{2-} / \mathrm{TiO}_{2}$ under the irradiation of (a) the $60 \mathrm{~W}$ LED lamp and (b) the sunlight.

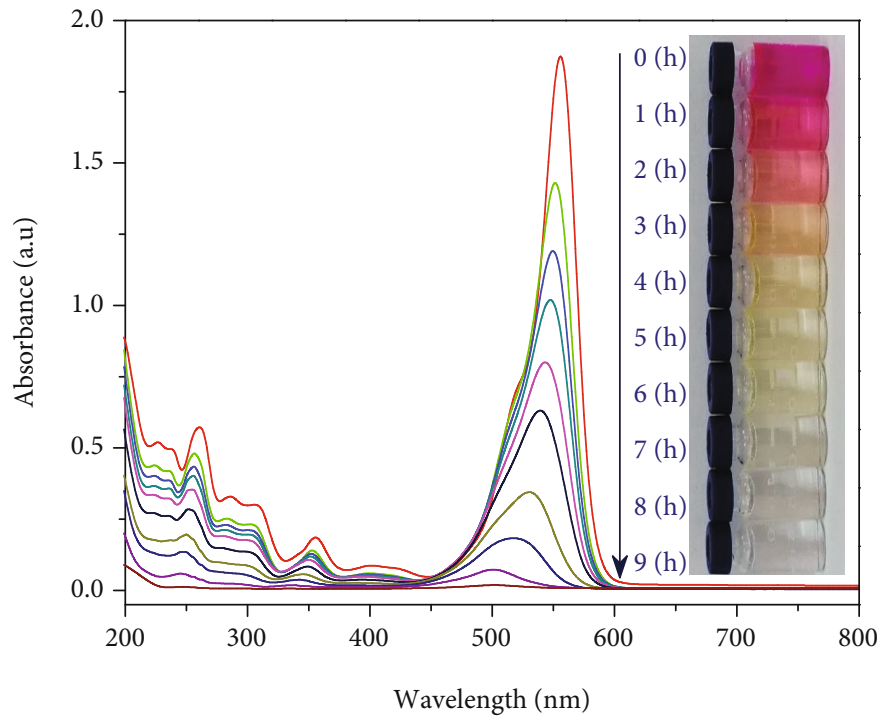

Figure 12: The UV-Vis absorption spectra for the photodegradation process of RhB solution for $\mathrm{SO}_{4}^{2-} / \mathrm{TiO}_{2}$ under the visible light irradiation.

UV-Vis molecular absorption spectra of RhB solution as a function of irradiation time shown in Figure 12 indicate that $\mathrm{RhB}$ was completely decomposed in the visible light region when the $\mathrm{SO}_{4}^{2-} / \mathrm{TiO}_{2}$ sample was used as a photocatalyst. Indeed, when continuously irradiating the reaction mixture between 01 and 09 hours by a $60 \mathrm{~W}$ LED lamp, the RhB photodegradation efficiency increases from 15.65 to $99.47 \%$ (Figure 11(a)). It is worth noting that the improvement of the photocatalytic activies over the $\mathrm{SO}_{4}{ }^{2-} / \mathrm{TiO}_{2}$ sample due to electrostatic interaction between negatively charge sul- phate titania and rhodamine $\mathrm{B}$ can be excluded since the $\mathrm{C} /$ $C_{0}$ in the case of the $\mathrm{SO}_{4}{ }^{2-} / \mathrm{TiO}_{2}$ presence hardly change if the LED light was turned off (Figure 11(a)).

The results from Figure 12 show that the absorption peak position of RhB at $553 \mathrm{~nm}$ is gradually shifted towards short wavelengths. The shift of absorption peaks during the photodegradation process of $\mathrm{RhB}$ solution can be explained by the fact that the $\mathrm{RhB}$ decomposition process will form a series of intermediates with a shorter conjugate $\pi$. The process of destroying the chromophore cleavage structure of the dye 


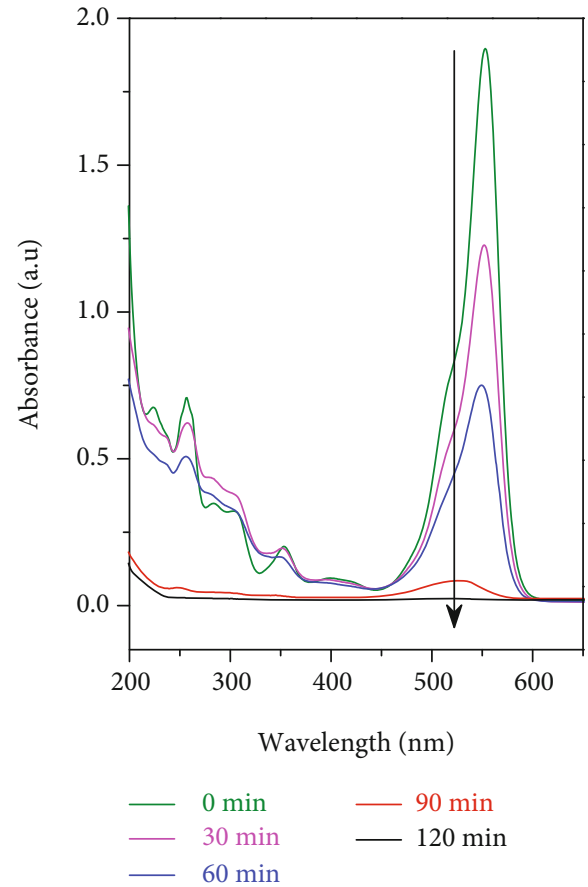

(a)

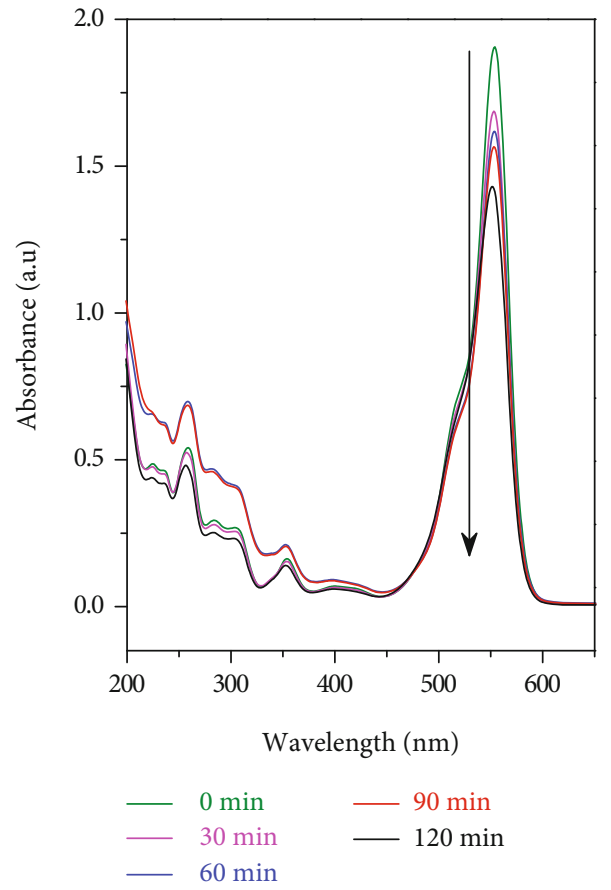

(b)

FIGURE 13: The UV-Vis absorption spectra for the photodegradation process of $\mathrm{RhB}$ solution under the sunlight irradiation for (a) $\mathrm{SO}_{4}{ }^{2-} / \mathrm{TiO}_{2}$ and (b) $\mathrm{TiO}_{2}$.

molecule is quite easy by dividing the conjugate $\pi$ system into $\pi$ shorter aromatic, homologous phenol intermediate products, etc. so that RhB will eventually be completely decomposed into $\mathrm{CO}_{2}$ and $\mathrm{H}_{2} \mathrm{O}$ [45].

When using the sunlight as a light source (intensity of 65,000 Lux), the RhB photodegradation efficiency for the $\mathrm{SO}_{4}{ }^{2-} / \mathrm{TiO}_{2}$ significantly increases. UV-Vis absorption spectra for the $\mathrm{RhB}$ photodegradation process of the $\mathrm{SO}_{4}{ }^{2-} / \mathrm{TiO}_{2}$ sample presented in Figure 13(a) reveal that after 2 hours of irradiation by the sunlight, the absorption peaks of $\mathrm{RhB}$ in both the visible and ultraviolet regions are almost no longer detected. It is worth noting that the $\mathrm{RhB}$ photodegradation efficiency for the $\mathrm{SO}_{4}{ }^{2-} / \mathrm{TiO}_{2}$ sample is about $99.63 \%$ while that for the $\mathrm{TiO}_{2}-550$ sample is only $26.09 \%$ (Table 1). Hence, the $\mathrm{SO}_{4}{ }^{2-}$ doping enhances the photocatalytic activities of the obtained sample.

The photocatalytic ability of the $\mathrm{SO}_{4}{ }^{2-} / \mathrm{TiO}_{2}$ sample when stimulated by the sunlight is much better than that of the $\mathrm{TiO}_{2}$ sample may be ascribed to two factors. Firstly, the $\mathrm{TiO}_{2}$ nondenatured sample only adsorbs photons in the ultraviolet light region while the $\mathrm{SO}_{4}{ }^{2-} / \mathrm{TiO}_{2}$ sample is capable of absorbing photons of light in both ultraviolet and visible regions. Since the radiation from the sunlight contains only about $5 \%$ of UV rays, so the $\mathrm{SO}_{4}{ }^{2-} / \mathrm{TiO}_{2}$ sample will have better optical absorption performance and thereby exhibiting higher photocatalytic activity compared with the $\mathrm{TiO}_{2}$ sample. Secondly, $\mathrm{SO}_{4}{ }^{2-}$ ions doped on the surface of the $\mathrm{TiO}_{2}$ have a strong electron affinity and thereby hindering the electron-hole recombination by capturing the photoinduced electrons [38]. This is in good agreement with the results of the PL spectra.
It is found that $\mathrm{RhB}$ was almost completely decomposed in the presence of the $\mathrm{SO}_{4}{ }^{2-} / \mathrm{TiO}_{2}$ sample as a photocatalyst and either the sunlight (Figure 13(a)) or the $60 \mathrm{~W}$ LED lamp (Figure 13) was used as an irradiation light source. However, the processing time for the $\mathrm{RhB}$ photodegradation of the $\mathrm{SO}_{4}{ }^{2-} / \mathrm{TiO}_{2}$ sample shortens when illuminated with the sunlight rather than the $60 \mathrm{~W}$ LED lamp (2 and 9 hours, respectively). This is due to the fact that in the experimental conditions, the sunlight has a higher illumination than incandescent light sources. Therefore, under the irradiation of the sunlight, the $\mathrm{SO}_{4}{ }^{2-} / \mathrm{TiO}_{2}$ sample absorbs both visible and $\mathrm{UV}$ energies to catalyze the reaction.

All things considered, the $\mathrm{SO}_{4}{ }^{2-}$ doping in the $\mathrm{TiO}_{2}$ narrows the bandgap and reduces the recombination of the photoinduced electrons and holes, thereby making the $\mathrm{SO}_{4}{ }^{2-} / \mathrm{TiO}_{2}$ sample such a promising candidate for the photodegradation of $\mathrm{RhB}$ solution under the illumination of both the visible light and sunlight.

Reusability plays a pivotal role in choosing a photocatalyst for practical applications. The used $\mathrm{SO}_{4}{ }^{2-} / \mathrm{TiO}_{2}$ material was washed with distilled water at least three times before dried at $80^{\circ} \mathrm{C}$ for 12 hours for regeneration. The photodegradation efficiency of $\mathrm{RhB}$ over reused photocatalyst is presented in Figure 14. This result shows a slight decrease in the $\mathrm{RhB}$ decomposition efficiency as a function of recycling cycle. However, the RhB photodegradation efficiency still reached over $96.0 \%$ after three cycles of recycling. The XRD pattern of the $\mathrm{SO}_{4}{ }^{2-} / \mathrm{TiO}_{2}$ material (Figure 15) hardly changes, suggesting that the $\mathrm{SO}_{4}{ }^{2-} / \mathrm{TiO}_{2}$ material possesses excellent structural stability after three cycles of recycling. 


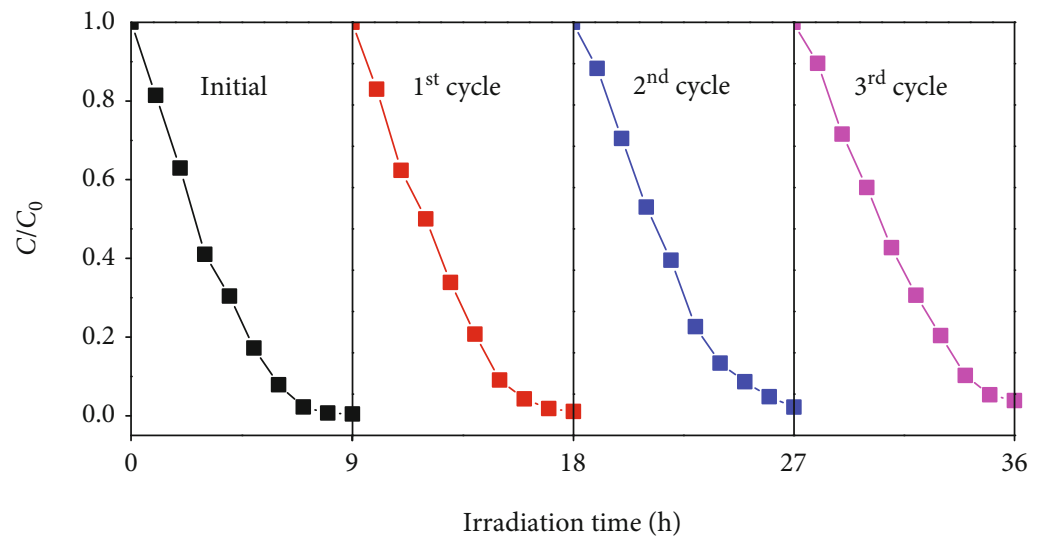

(a)

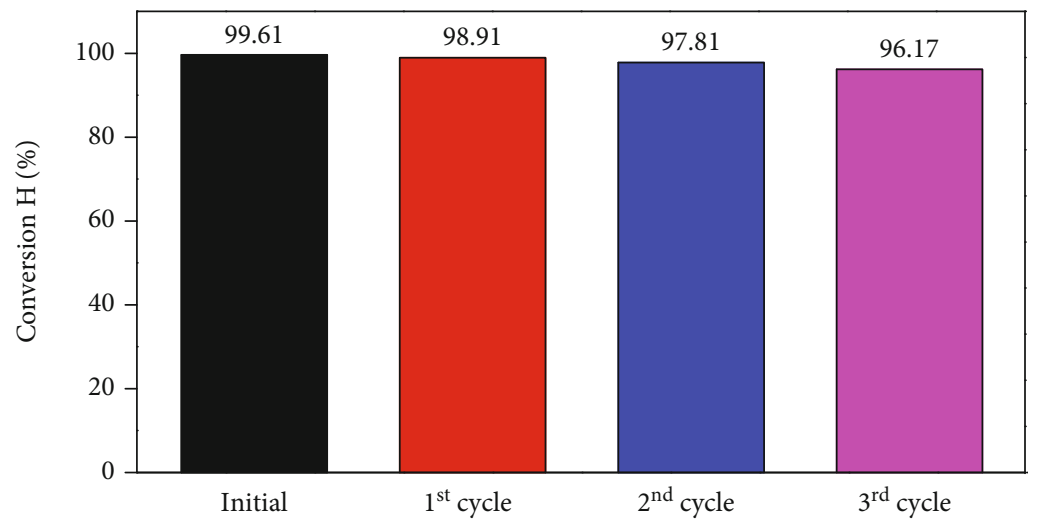

(b)

FIgURE 14: The change in $C / C_{0}$ as a function of irradiation time (a) and $\mathrm{RhB}$ photodegradation efficiency (b) after three cycles of recycling of the $\mathrm{SO}_{4}{ }^{2-} / \mathrm{TiO}_{2}$ material.

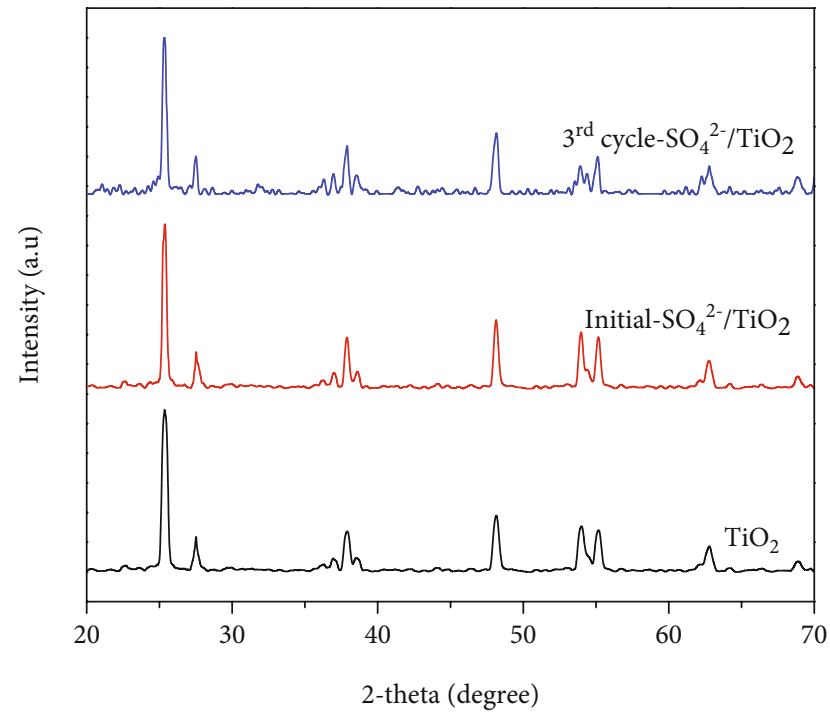

FIgure 15: XRD patterns for the $\mathrm{TiO}_{2}$, the initial $\mathrm{SO}_{4}{ }^{2-} / \mathrm{TiO}_{2}$ and the reused $\mathrm{SO}_{4}{ }^{2-} / \mathrm{TiO}_{2}$ after the third cycle.

\section{Conclusions}

Nanosized $\mathrm{SO}_{4}{ }^{2-} / \mathrm{TiO}_{2}$ nanoparticles have been successfully synthesized from $\mathrm{TiO}_{2}$ (prepared from Binh Dinh ilmenite ore) and characterized by modern chemicalphysical methods. The experimental results indicate that the formation of Ti-O-S and the chemical adsorption of $\mathrm{SO}_{4}{ }^{2-}$ ions on the $\mathrm{TiO}_{2}$ surface have shifted the optical absorption band of the obtained sample into the visible light region with the bandgap energy $\left(E_{g}\right)$ of $2.75 \mathrm{eV}$. With the purpose of manufacturing samples with high photocatalytic activities in the visible light region, the nanosized $\mathrm{SO}_{4}{ }^{2-} / \mathrm{TiO}_{2}$ sample is considered as a highly promising candidate for the $\mathrm{RhB}$ photodegradation owing to its high photodegradation efficiency under the illumination of both the visible light and sunlight. It is noted that the time treatment is greatly reduced when using the sunlight as an illumination source rather than the $60 \mathrm{~W}$ LED lamp.

\section{Data Availability}

The data used to support the findings of this study are available from the corresponding author upon request.

\section{Conflicts of Interest}

The authors declare that they have no conflicts of interest. 


\section{Acknowledgments}

This research is sponsored by Vietnamese Ministry of Education and Training under the project with code number B2019-DQN-13.

\section{References}

[1] Y. Yang, M. Yang, Z. Zheng, and X. Zhang, "Highly effective adsorption removal of perfluorooctanoic acid (PFOA) from aqueous solution using calcined layer-like $\mathrm{Mg}$ - $\mathrm{Al}$ hydrotalcites nanosheets," Environemental Science and Pollution Research, vol. 27, no. 12, pp. 13396-13408, 2020.

[2] Y. Wang, L. Yu, R. Wang, Y. Wang, and X. Zhang, "A novel cellulose hydrogel coating with nanoscale $\mathrm{Fe}^{0}$ for $\mathrm{Cr}(\mathrm{VI})$ adsorption and reduction," Science of the Total Environment, vol. 726, article 138625, 2020.

[3] Y. Yang, Z. Zheng, D. Zhang, and X. Zhang, "Response surface methodology directed adsorption of chlorate and chlorite onto MIEX resin and study of chemical properties," Environmental Science: Water Research \& Technology, vol. 6, no. 9, pp. 24542464, 2020.

[4] Y. Wang, L. Yu, R. Wang, Y. Wang, and X. Zhang, "Microwave catalytic activities of supported perovskite catalysts $\mathrm{MO}_{\mathrm{x}} / \mathrm{La}-$ $\mathrm{Co}_{0.5} \mathrm{Cu}_{0.5} \mathrm{O}_{3} @ \mathrm{CM}(\mathrm{M}=\mathrm{Mg}, \mathrm{Al})$ for salicylic acid degradation," Journal of Colloid and Interface Science, vol. 564, pp. 392-405, 2020.

[5] Y. Wang, Y. Wang, L. Yu, R. Wang, and X. Zhang, "Highly effective microwave-induced catalytic degradation of Bisphenol A in aqueous solution using double-perovskite intercalated montmorillonite nanocomposite," Chemical Engineering Journal, vol. 390, article 124550, 2020.

[6] D. B. Miklos, C. Remy, M. Jekel, K. G. Linden, J. E. Drewes, and U. Hubner, "Evaluation of advanced oxidation processes for water and wastewater treatment - a critical review," Water Research, vol. 139, pp. 118-131, 2018.

[7] P. Raizada, A. Sudhaik, P. Shandilya, A. Saini, V. Gupta, and P. Singh, "Fabrication of $\mathrm{Ag}_{3} \mathrm{VO}_{4}$ decorated phosphorus and sulphur co-doped graphitic carbon nitride as a highdispersed photocatalyst for phenol mineralization and E. coli disinfection," Separation and Purification Technology, vol. 212, pp. 887-900, 2019.

[8] B. Pare, P. Singh, and S. B. Jonnalagadda, "Visible light-driven photocatalytic degradation and mineralization of neutral red dye in a slurry photoreacter," Indian Journal of Chemical Technology, vol. 17, pp. 391-395, 2010.

[9] P. Singh, P. Raizada, D. Pathania, A. Kumar, and P. Thakur, "Preparation of BSA-ZnWO4 nanocomposites with enhanced adsorptional photocatalytic activity for methylene blue degradation," International Journal of Photoenergy, vol. 2013, 7 pages, 2013.

[10] U. I. Gaya and A. H. Abdullah, "Heterogeneous photocatalytic degradation of organic contaminants over titanium dioxide: a review of fundamentals, progress and problems," Journal of Photochemistry and Photobiology C, vol. 9, no. 1, pp. 1-12, 2008.

[11] X. Chen, Z. Wu, D. Liu, and Z. Gao, "Preparation of $\mathrm{ZnO}$ photocatalyst for the efficient and rapid photocatalytic degradation of azo dyes," Nanoscale Research Letters, vol. 12, no. 1, p. 143, 2017.

[12] X. Liu, H. Zhai, P. Wang et al., "Synthesis of a $\mathrm{WO}_{3}$ photocatalyst with high photocatalytic activity and stability using syn- ergetic internal $\mathrm{Fe}^{3+}$ doping and superficial Pt loading for ethylene degradation under visible-light irradiation," Catalysis Science \& Technology, vol. 9, no. 3, pp. 652-658, 2019.

[13] W. Hussain, H. Malik, A. Bahadur et al., "Synthesis and characterization of CdS photocatalyst with different morphologies: visible light activated dyes degradation study," Kinetics and Catalysis, vol. 59, no. 6, pp. 710-719, 2018.

[14] Z. Li, X. Meng, and Z. Zhang, "Recent development on $\mathrm{MoS}_{2}$ based photocatalysis: a review," Journal of Photochemistry and Photobiology C, vol. 35, pp. 39-55, 2018.

[15] A. Malathi, J. Madhavan, M. Ashokkumar, and P. Arunachalam, "A review on $\mathrm{BiVO}_{4}$ photocatalyst: activity enhancement methods for solar photocatalytic applications," Applied Catalysis A: General, vol. 555, pp. 47-74, 2018.

[16] H. Kim, S. Lee, Y. Han, and J. Park, "Preparation of dip-coated $\mathrm{TiO}_{2}$ photocatalyst on ceramic foam pellets," Journal of Materials Science, vol. 40, no. 19, pp. 5295-5298, 2005.

[17] K. Hashimoto, H. Irie, and A. Fujishima, "TiO2Photocatalysis: a historical overview and future prospects," Japanese Journal of Applied Physics, vol. 44, no. 12, pp. 8269-8285, 2005.

[18] W. Y. Choi, A. Termin, and M. R. Hoffmann, "The role of metal ion dopants in quantum-sized $\mathrm{TiO}_{2}$ : correlation between photoreactivity and charge carrier recombination dynamics," The Journal of Physical Chemistry, vol. 98, no. 51, pp. 1366913679, 1994.

[19] U. G. Akpan and B. H. Hameed, "The advancements in sol-gel method of doped- $\mathrm{TiO}_{2}$ photocatalysts," Applied Catalysis A: General, vol. 375, no. 1, pp. 1-11, 2010.

[20] D. Chatterjee and S. Dasgupta, "Visible light induced photocatalytic degradation of organic pollutants," Journal of Photochemistry and Photobiology C: Photochemistry Reviews, vol. 6, no. 2-3, pp. 186-205, 2005.

[21] C. Jin, R. Y. Zheng, Y. Guo, J. L. Xie, Y. X. Zhu, and Y. C. Xi, "Hydrothermal synthesis and characterization of phosphorous-doped $\mathrm{TiO}_{2}$ with high photocatalytic activity for methylene blue degradation," Journal of Molecular Catalysis A: Chemical, vol. 313, no. 1-2, pp. 44-48, 2009.

[22] Y. Wu, J. Zhang, L. Xiao, and N. Chen, "Properties of carbon and iron modified $\mathrm{TiO}_{2}$ photocatalyst synthesized at low temperature and photodegradation of acid orange 7 under visible light," Applied Surface Science, vol. 256, no. 13, pp. 42604268, 2010.

[23] L. Huang, H. Xu, Y. Li et al., "Visible-light-induced $\mathrm{WO}_{3} / \mathrm{g}$ $\mathrm{C}_{3} \mathrm{~N}_{4}$ composites with enhanced photocatalytic activity," Dalton Transactions, vol. 42, no. 24, pp. 8606-8616, 2013.

[24] J. Wang and W.-D. Zhang, "Modification of $\mathrm{TiO}_{2}$ nanorod arrays by graphite-like $\mathrm{C}_{3} \mathrm{~N}_{4}$ with high visible light photoelectrochemical activity," Electrochimica, vol. 71, pp. 10-16, 2012.

[25] K. Sridharan, E. Jang, and T. J. Park, "Novel visible light active graphitic $\mathrm{C}_{3} \mathrm{~N}_{4}-\mathrm{TiO}_{2}$ composite photocatalyst: Synergistic synthesis, growth and photocatalytic treatment of hazardous pollutants," Applied Catalysis B: Environmental, vol. 142-143, pp. 718-728, 2013.

[26] J. Liu, L. Ruan, and S. Adeloju, "BiOI/TiO 2 nanotube arrays, a unique flake-tube structured $\mathrm{p}-\mathrm{n}$ junction with remarkable visible-light photoelectrocatalytic performance and stability," Dalton Transactions, vol. 43, no. 4, pp. 1706-1715, 2014.

[27] K. Wang, C. Shao, X. Li, F. Miao, N. Lu, and Y. Liu, "Heterojunctions of $\mathrm{p}$ - $\mathrm{BiOI}$ nanosheets $/ \mathrm{n}-\mathrm{TiO}_{2}$ nanofibers: preparation and enhanced visible-light photocatalytic activity," Materials, vol. 9, no. 2, p. 90, 2016. 
[28] G. Zhang, S. Ji, Y. Zhang, and Y. Wei, "Facile synthesis of p-n heterojunction of phosphorus doped $\mathrm{TiO}_{2}$ and $\mathrm{BiOI}$ with enhanced visible-light Photocatalytic activity," Solid State Communication, vol. 259, pp. 34-39, 2017.

[29] B. Wang, L. Li, J. Chen et al., "Synthesis of $\mathrm{BiOCl}_{0.5} \mathrm{I}_{0.5} / \mathrm{TiO}_{2}$ heterojunctions with enhanced visible-light photocatalytic properties," Journal of Nanoparticle Research, vol. 20, no. 7, pp. 1-13, 2018.

[30] B. Krishnakumar, R. Hariharan, V. Padiyan, A. Aguiar, and A. J. F. N. Sobral, "Gelatin-assisted $\mathrm{g}-\mathrm{TiO}_{2} / \mathrm{BiOI}$ heterostructure nanocomposites for azo dye degradation under visible light," Journal of Environmental Chemical Engineering, vol. 6, no. 4, pp. 4282-4288, 2018.

[31] G. Sui, J. Li, D. Lijuan et al., "Preparation and characterization of $g-\mathrm{C}_{3} \mathrm{~N}_{4} / \mathrm{Ag}$ - $\mathrm{TiO}_{2}$ ternary hollowsphere nanoheterojunction catalyst with high visible light photocatalytic performance," Journal of Alloys and Compounds, vol. 823, article 153851, 2020.

[32] S. Jia, J. Li, G. Sui et al., "Synthesis of 3D flower-like structured Gd/TiO2@rGO nanocompositesviaa hydrothermal method with enhanced visible-light photocatalytic activity," RSC Advances, vol. 9, no. 53, pp. 31177-31185, 2019.

[33] J. Chen, X. Zhang, F. Bi, X. Zhang, Y. Yang, and Y. Wang, "A facile synthesis for uniform tablet-like $\mathrm{TiO}_{2} / \mathrm{C}$ derived from Materials of Institut Lavoisier-125(Ti) (MIL-125(Ti)) and their enhanced visible light-driven photodegradation of tetracycline," Journal of Colloid and Interface Science, vol. 571, pp. 275-284, 2020.

[34] L. B. McCusker, "Product characterization by X-ray powder diffraction," Microporous and Mesoporous Materials, vol. 22, no. 4-6, pp. 527-529, 1998.

[35] R. A. Spurr and H. Myers, "Quantitative analysis of anataserutile mixtures with an X-ray diffractometer," Analytical Chemistry, vol. 29, no. 5, pp. 760-762, 1957.

[36] H. Nishikiori, M. Hayashibe, and T. Fujii, "Visible lightphotocatalytic activity of sulfate-doped titanium dioxide prepared by the sol-gel method," Catalysts, vol. 3, no. 2, pp. 363-377, 2013.

[37] T. Umebayashi, T. Yamaki, H. Itoh, and K. Asai, "Band gap narrowing of titanium dioxide by sulfur doping," Applied Physics Letters, vol. 81, no. 3, pp. 454-456, 2002.

[38] Y. Niu, M. Xing, B. Tian, and J. Zhang, "Improving the visible light photocatalytic activity of nano-sized titanium dioxide via the synergistic effects between sulfur doping and sulfation," Applied Catalysis B: Environmental, vol. 115-116, pp. 253260, 2012.

[39] T. Ohno, "Preparation of visible light active S-doped $\mathrm{TiO}_{2}$ photocatalysts and their photocatalytic activities," Water Science and Technology, vol. 49, no. 4, pp. 159-163, 2004.

[40] J. L. Ropero-Vegaa, A. Aldana-Pérez, R. Gómez, and M. E. Nino-Gómeza, "Sulfated titania $\left[\mathrm{TiO}_{2} / \mathrm{SO}_{4}{ }^{2-}\right]$ : a very active solid acid catalyst for the esterification of free fatty acids with ethanol," Applied Catalysis A: General, vol. 379, no. 1-2, pp. 24-29, 2010.

[41] J.-J. Guo, T.-S. Jin, S.-L. Zhang, and T.-S. Li, " $\mathrm{TiO}_{2} / \mathrm{SO}_{4}{ }^{2-}$ : an efficient and convenient catalyst for preparation of aromatic oximes," Green Chemistry, vol. 3, no. 4, pp. 193-195, 2001.

[42] M. J. Seong, O. Dupont, and P. Grange, " $\mathrm{TiO}_{2}-\mathrm{SiO}_{2}$ mixed oxide modified with $\mathrm{H}_{2} \mathrm{SO}_{4}$ : I. Characterization of the microstructure of metal oxide and sulfate," Applied Catalysis A: General, vol. 208, no. 1-2, pp. 393-401, 2001.
[43] Y. Liu, J. Liu, Y. Lin, Y. Zhang, and Y. Wei, "Simple fabrication and photocatalytic activity of S-doped $\mathrm{TiO}_{2}$ under low power LED visible light irradiation," Ceramics International, vol. 35, no. 8, pp. 3061-3065, 2009.

[44] G. Liu, C. Sun, S. C. Smith, L. Wang, G. Q. Lu, and H.M. Cheng, "Sulfur doped anatase $\mathrm{TiO}_{2}$ single crystals with a high percentage of $\left\{\begin{array}{lll}0 & 0 & 1\end{array}\right\}$ facets," Journal of Colloid and Interface Science, vol. 349, no. 2, pp. 477-483, 2010.

[45] S. S. P. Selvin, A. G. Kumar, L. Sarala et al., "Photocatalytic degradation of rhodamine B using zinc oxide activated charcoal polyaniline nanocomposite and its survival assessment using aquatic animal model," ACS Sustainable Chemistry \& Engineering, vol. 6, pp. 258-267, 2018. 